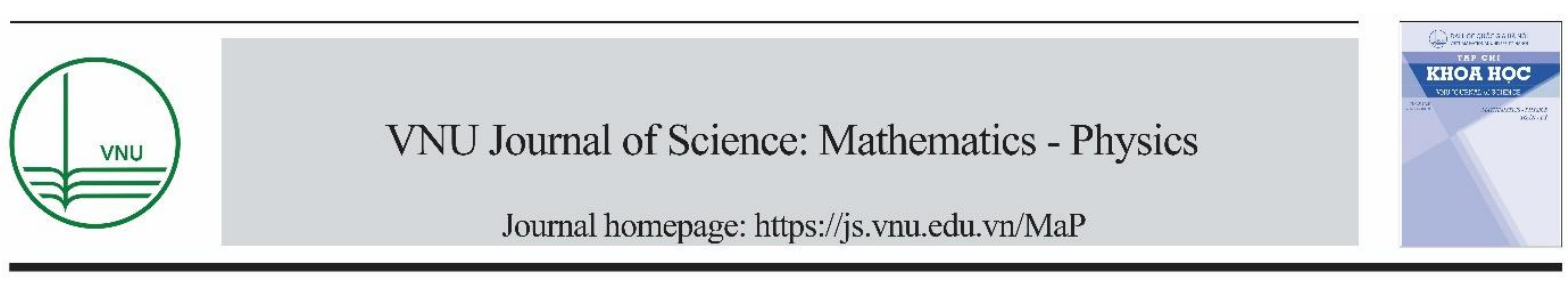

Original Article

\title{
Optimization of Laminated Composite Plates for Maximum Biaxial Buckling Load
}

\author{
Pham Dinh Nguyen ${ }^{1}$, Quang-Viet Vu², George Papazafeiropoulos ${ }^{3}$, \\ Hoang Thị Thiem ${ }^{1}$, Pham Minh Vuong ${ }^{1}$, Nguyen Dinh Duc ${ }^{1, *}$ \\ ${ }^{I}$ Advanced Materials and Structures Laboratory, VNU University of Engineering and Technology, \\ Vietnam National University, Hanoi, 144 Xuan Thuy, Cau Giay, Hanoi, Vietnam \\ ${ }^{2}$ Faculty of Civil Engineering, Vietnam Maritime University, 484 Lach Tray, Hai Phong, Vietnam \\ ${ }^{3}$ Department of Structural Engineering, National Technical University of Athens, \\ Zografou, Athens 15780, Greece
}

Received 11 April 2020; Accepted 05 May 2020

\begin{abstract}
This paper proposes an optimization procedure for maximization of the biaxial buckling load of laminated composite plates using the gradient-based interior-point optimization algorithm. The fiber orientation angle and the thickness of each lamina are considered as continuous design variables of the problem. The effect of the number of layers, fiber orientation angles, thickness and length to thickness ratios on the buckling load of the laminated composite plates under biaxial compression is investigated. The effectiveness of the optimization procedure in this study is compared with previous works.
\end{abstract}

Keywords: Optimum design, Fiber angles, Biaxial compression, Laminated composite plates, Abaqus2Matlab.

\section{Introduction}

Composite materials are widely applied in many heavy duty engineering structures. Composite materials are lightweight and they have low density, high strength and high stiffness. Those properties are a results of the characteristics of the main constituents of composite materials. Therefore, the optimal design of the latter depends on the design of their various components. Optimization problems involving

\footnotetext{
* Corresponding author.

Email address: ducnd@vnu.edu.vn
}

https//doi.org/ 10.25073/2588-1124/vnumap.4509 
laminated composite plates are often sophisticated because of the numerous design variables and their complex behavior which depends on the properties of the laminae.

In recent years, many studies have been published for the buckling analysis of the laminated composite structures subjected to various loads. The analysis of composite plates using finite element methods (FEMs) has been reported by applying the first-order shear deformation theory (FSDT), Wang et al. [1] presented the results of natural frequencies and buckling load of the laminated composite plates, Ferreira et al. [2] shown the critical buckling load of isotropic and laminated plates, Nguyen-Van et al. [3] presented the free vibration and buckling analysis of composite plates and shells using a smoothed quadrilateral flat element, Thai et al. [4] studied the static, free vibration, and buckling analysis of laminated composite plates with quadratic, cubic, and quartic elements. By using the higher-order shear deformation theories (HSDT), the results of critical buckling load and natural frequencies of cross-ply laminated plates had been reported by Khdeir and Librescu [5] and Faces and Zenkour [6], Chakrabarti and Sheikh [7] investigated the buckling analysis of laminated composite plates using a triangular element. The buckling analysis of composite structures using an analytical method has been reported by Duc et al. [8,9] using the FSDT for the composite plates resting on elastic foundations, Le et al. [10] presented the nonlinear buckling analysis of functionally graded graphene-reinforced composite laminated cylindrical shells under axial compressive load. The buckling analysis of composite plates and shells using a semi-analytical method has been reported by Kermanidis and Labeas [11] and Mohammad and Arabi [12].

The optimum design is a significant problem in structural engineering which is intended to increase the performance of structures. The optimum values of fiber angles for maximizing the buckling load of the laminated composite plates has been investigated in $[13,14]$ where the plate had been subjected to uniaxial compression [13], bending load and both [14] under various boundary conditions. Studies for the optimal design of the stacking sequence have been carried out by Riche and Haftka [15] using a genetic algorithm, Jing et al. [16] using a permutation search algorithm and Almeida [17] using a harmony search algorithm, Bargh and Sadr [18] using a the particle swarm optimization algorithm. Both fiber angles and thickness are used as design variables to obtain the maximum buckling load in the studies by Huang and Kroplin [19] using a variable metric algorithm, Akbulut and Sonmez [20] using the simulated annealing algorithm, Ho-Huu et al. [21] using an improved differential evolution algorithm. Chandrasekhar et al. [22] studied the topology optimization of laminated composite plates and shells using optimality criteria.

From the above literature review, this paper proposes a new optimization procedure for the laminated composite plates subjected to biaxial compression to obtain maximizing buckling load with design variables are fiber angles and thickness. The optimization procedure is implemented by using Abaqus2Matlab [23] which is designed for transferring model and/or results data from Abaqus to Matlab and vice versa to generate the necessary Abaqus input files, run the analysis and extract the analysis results in Matlab.

\section{Methodology}

\subsection{Buckling Analysis of Laminated Composite Plates}

Consider a laminated composite plate that is subjected to biaxial compression, as shown in Figure 1. The composite plate consists of $\mathrm{n}$ laminae, each one having its own fiber angle and thickness. The total thickness, length and width of the plate are $h, a, b$, respectively. 


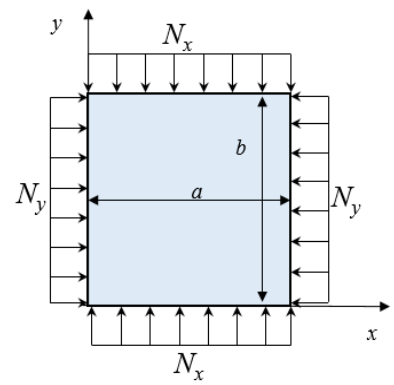

a. Coss-section of lamina.

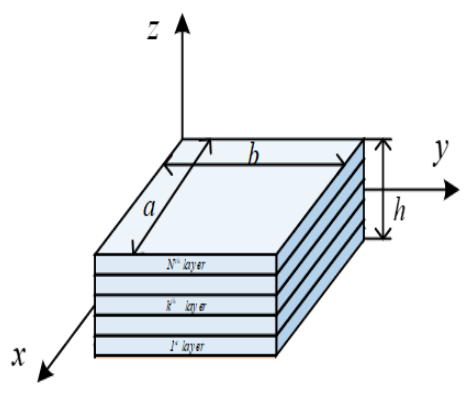

b. Layers of the plate.

Fig. 1. Model of the composite laminated plate subjected to biaxial load.

In the buckling analysis, the eigenvalues $\left(\lambda_{i}\right)$ and buckling mode shapes $\left(\phi_{i}\right)$ are obtained by solving the eigenvalue problem:

$$
\left([K]+\lambda_{i}[\sigma]\right) \phi_{i}=0
$$

in which, $[K],[\sigma]$ are the stiffness and stress matrices, respectively.

The critical eigenvalue buckling analysis ( the first eigenvalue $\lambda_{c r}$ ) is used to determine the critical buckling load $\left(F_{c r}\right)$ with $\mathrm{N}$ is the applied load as follows:

$$
F_{c r}=\lambda_{c r} N
$$

The buckling coefficient of the laminated composite plates is determined by:

$$
k=\frac{\lambda_{c r} a^{2}}{E_{2} h^{3}}
$$

\subsection{Optimization Method}

\subsubsection{Statement of the Problem}

The objective of the optimization problem is to maximize the biaxial buckling load factor of the composite plate. The design variables of the optimization problem are the fiber angles and the thicknesses of the laminae of the composite plate, which are continuous variables. The optimization problem contains an equality constraint, stating that the sum of the laminae thicknesses be equal to the total thickness of the plate.

The optimization problem is mathematically described as:

Maximize:

$$
\lambda_{c r}\left(t_{i}, \theta_{i}\right)
$$

Subject to $\sum_{i=1}^{n} t_{i}=h, \quad t_{l b} \leq t_{i} \leq t_{u b}, \theta_{l b} \leq \theta_{i} \leq \theta_{u b}, i=\overline{1 \div n}$,

in which, $t_{i}$ is the $\mathrm{i}^{\text {th }}$ lamina thickness which varies from lower bound $t_{l b}$ to upper bound $t_{u b}, \theta_{i}$ is the fiber angle of the $\mathrm{i}^{\text {th }}$ lamina which varies from $\theta_{l b}=-90^{\circ}$ to $\theta_{u b}=90^{\circ}$. 


\subsubsection{Proposed Optimization Procedure}

This section presents an optimization procedure using the gradient-based interior point algorithm (IPA) to calculate the optimum fiber angles and thickness of the laminated composite plates. This optimization procedure integrates Matlab and Abaqus in a loop with the use of Abaqus2Matlab, which is developed by Papazafeiropoulos et al. [23]. All steps of this optimization process are described in Figure 2 .

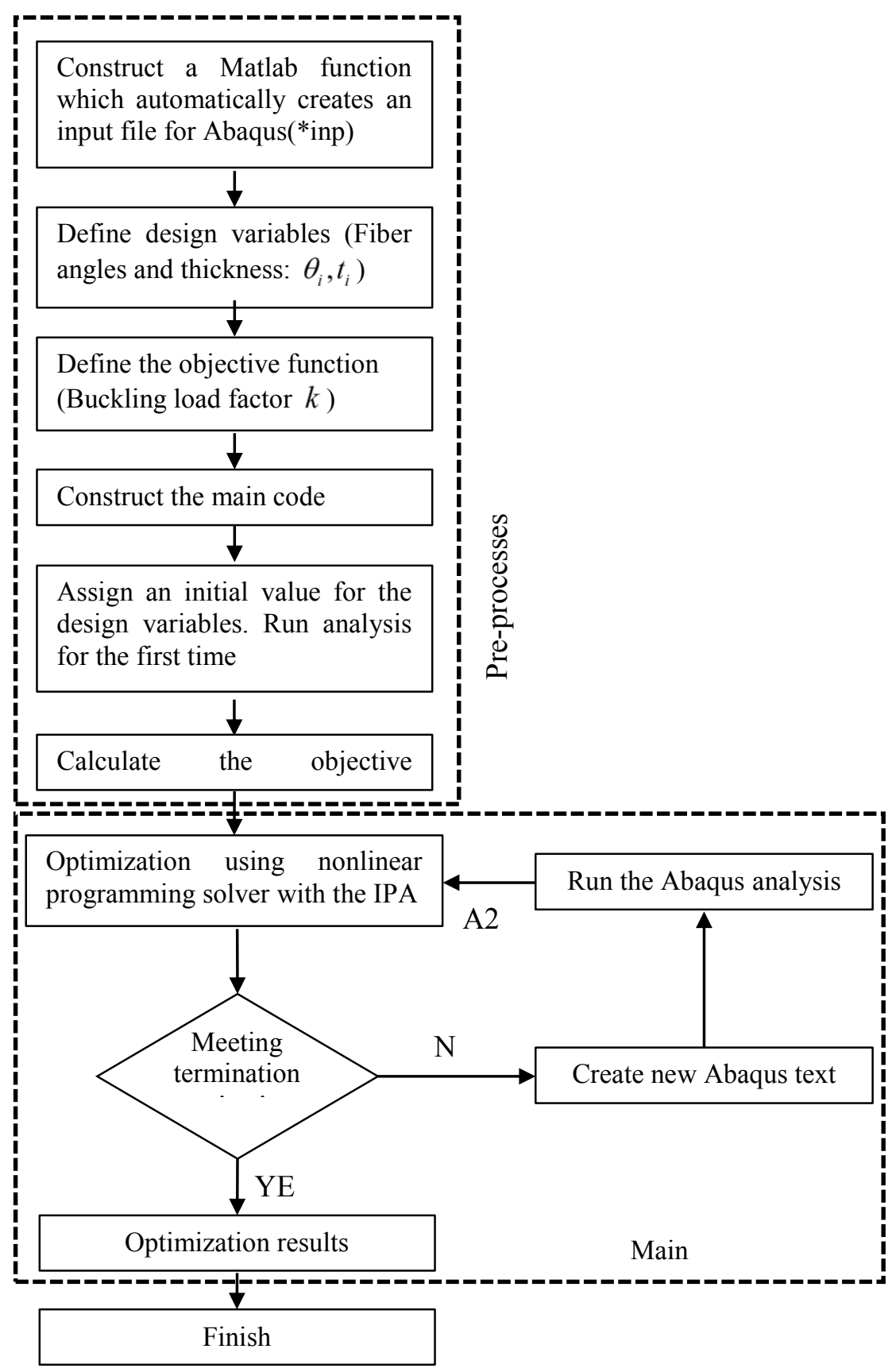

Fig. 2. Flowchart of the optimization procedure. 


\section{Numerical Results and Discussions}

\subsection{Validation}

In this section, the buckling coefficient $k=\frac{\lambda_{c r} a^{2}}{E_{2} h^{3}}$ of the laminated composite plates under uniaxial and biaxial compression are compared with previous works. The material properties of the laminated composite plates is given as follows: $E_{1} / E_{2}=40, G_{12}=G_{13}=0.6 E_{2}, G_{23}=0.5 E_{2}, v_{12}=0.25$, $a=b=1, a / h=10$. Tables 1 and 2 compare the buckling load factors of the laminated composite plates (16x16 elements) to verify the Abaqus model developed in this study. Tables 3 and 4 present the comparison results of the optimization of fiber angles and thickness of the laminated composite plates (12x12 elements) when the number of layers is 3,4 , and 10 .

From the comparison, it can be shown that the developed model in this paper is reliable to use for the analysis of the laminated composite plates. The last column of Tables 3 and 4 contains the number of structural analyses (NSA) required to reach the optimum solution

Table 1. Comparison of the buckling load factors of [0/90] 5 laminated plates under uniaxial compression

\begin{tabular}{|l|l|l|l|l|l|l|}
\hline & SSSS & SSCC & SSSC & SSFC & SSFS & SSFF \\
\hline Wang et al. [1] & 25.703 & 35.162 & 32.95 & 14.495 & 12.658 & 12.224 \\
\hline Nguyen et al. [3] & 25.534 & 34.531 & 32.874 & 14.356 & 12.543 & 12.131 \\
\hline Thai et al. [4] & 25.5269 & 35.1784 & 32.6882 & 14.4828 & 12.6174 & 12.2338 \\
\hline Ho-Huu et al. [21] & 25.2562 & 35.0937 & 32.7586 & 14.3433 & 12.4929 & - \\
\hline Present study & 25.2411 & 34.0573 & 31.955 & 14.2248 & 12.4172 & 11.992 \\
\hline
\end{tabular}

Table 2. Comparison of the buckling load factors of SSSS [0/90/0] square plates under biaxial compression

\begin{tabular}{|l|l|l|l|l|}
\hline$E_{1} / E_{2}$ & 10 & 20 & 30 & 40 \\
\hline Nguyen et al. [3] & 4.939 & 7.488 & 9.016 & 10.252 \\
\hline Thai et al. [4] & 4.9958 & 7.5155 & 8.8712 & 10.0525 \\
\hline Khdeir and Librescu [5] & 4.963 & 7.516 & 9.056 & 10.259 \\
\hline Fares and Zenkour [6] & 4.963 & 7.588 & 8.575 & 10.202 \\
\hline Present study & 4.9461 & 7.458 & 8.6595 & 9.6655 \\
\hline
\end{tabular}

Table 3. Comparison of the optimum ply-angle of SSSS square composite plates under biaxial compression

\begin{tabular}{|c|c|c|c|c|}
\hline & No of layers & {$\left[\theta_{i}^{o}\right]$} & $k$ & NSA \\
\hline \multirow{2}{*}{ Ho-Huu et al. [21] } & \multirow{4}{*}{$3\left[\theta_{1} / \theta_{2} / \theta_{3}\right]$} & {$[0 / 90 / 0]$} & 10.23938 & 1 \\
\hline & & [45/-45/-45] & 12.37798 & 960 \\
\hline \multirow{2}{*}{ Present study } & & {$[0 / 90 / 0]$} & 9.7377 & 1 \\
\hline & & {$[45 /-45 / 45]$} & 11.232 & 99 \\
\hline \multirow{2}{*}{ Ho-Huu et al. [21] } & \multirow{4}{*}{$\begin{array}{l}4 \\
{\left[\theta_{1} / \theta_{2}\right] \mathrm{s}}\end{array}$} & {$[0 / 90]_{s}$} & 11.68617 & 1 \\
\hline & & {$[-45 / 45]_{s}$} & 15.66063 & 520 \\
\hline \multirow{2}{*}{ Present study } & & {$[0 / 90]_{s}$} & 11.634 & 1 \\
\hline & & {$[-45 / 45]_{s}$} & 14.871 & 68 \\
\hline
\end{tabular}




\begin{tabular}{|l|l|l|l|l|}
\hline \multirow{3}{*}{ Ho-Huu et al. [21] } & \multirow{4}{*}{10} & {$[0 / 90]_{5}$} & 12.71699 & 1 \\
\cline { 3 - 5 } & {$\left[\theta_{1} / \theta_{2} / \theta_{3} / \theta_{4} / \theta_{5}\right] \mathrm{s}$} & {$[45 /-45 /-45 /-45 / 45]_{s}$} & 19.50038 & 1040 \\
\cline { 3 - 5 } Present study & {$[0 / 90]_{5}$} & 12.671 & 1 \\
\cline { 3 - 5 } & {$[45 /-45 /-45 /-45 / 45]_{s}$} & 19.524 & 242 \\
\hline
\end{tabular}

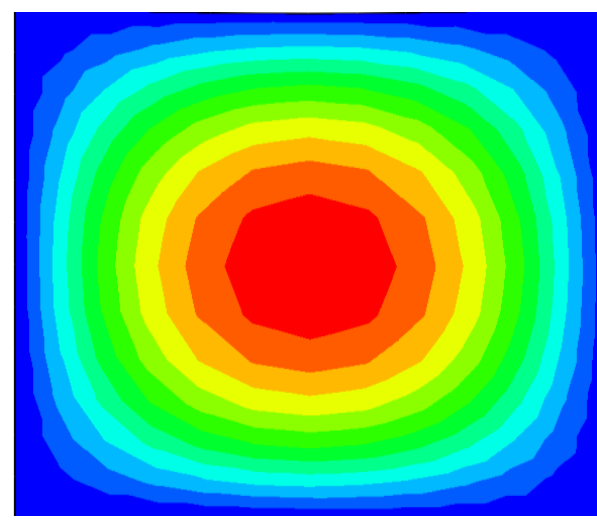

a. SSSS

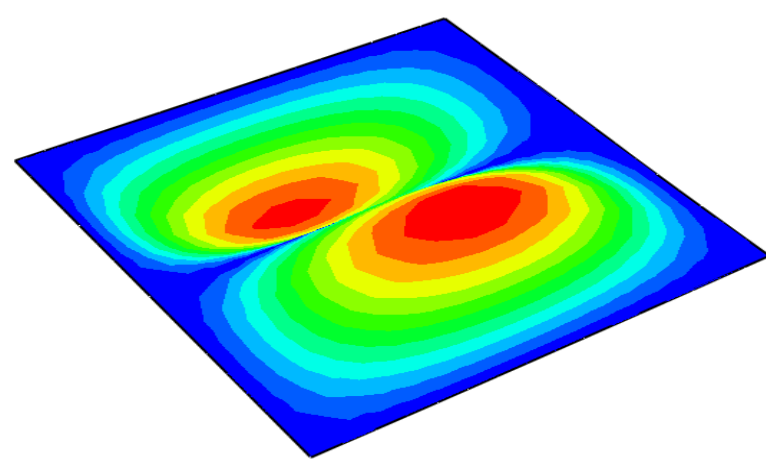

c. SSSC

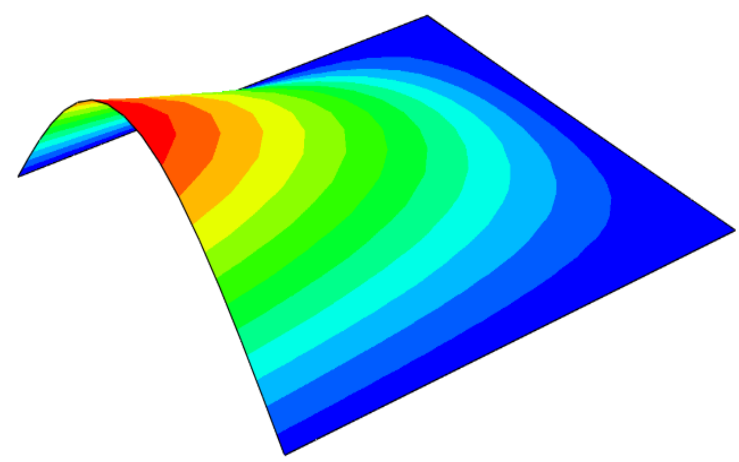

e. SSFS

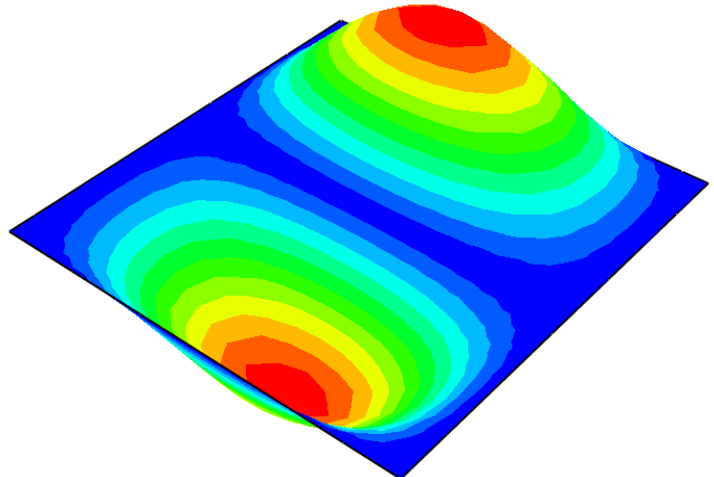

b. SSCC

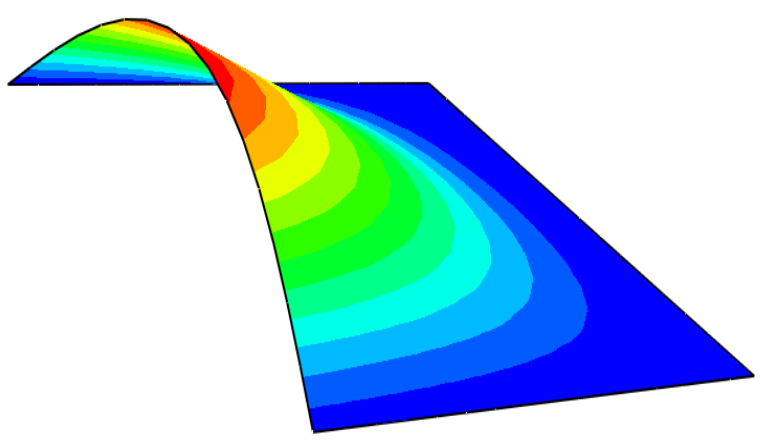

d. SSFC

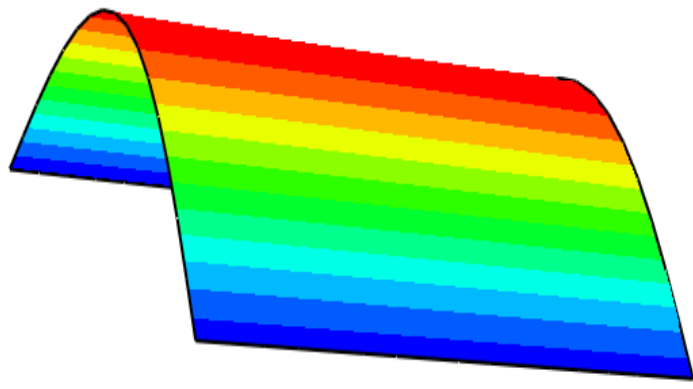

f. SSFF

Fig. 3. Buckling modes of laminated plates with various boundary conditions. 
Table 4. Comparison the optimum ply-angle and thickness of SSSS square composite plates under bixial compression

\begin{tabular}{|c|c|c|c|c|}
\hline & No of layers & {$\left[\theta_{i}^{0} ; t_{i}\left(10^{-3}\right)\right]$} & $k$ & NSA \\
\hline \multirow{2}{*}{$\begin{array}{l}\text { Ho-Huu et al. } \\
{[21]}\end{array}$} & \multirow{4}{*}{$\begin{array}{l}3 \\
{\left[\theta_{1} / \theta_{2} / \theta_{3}\right]} \\
{\left[t_{1} / t_{2} / t_{3}\right]}\end{array}$} & {$[45 /-45 / 45]$} & \multirow{2}{*}{19.49077} & \multirow{2}{*}{2180} \\
\hline & & [10.213/79.539/10.247] & & \\
\hline \multirow{2}{*}{ Present study } & & {$[45 /-45 / 45]$} & \multirow{2}{*}{19.5043} & \multirow{2}{*}{208} \\
\hline & & [9.5996/80.8009/9.5996] & & \\
\hline \multirow{2}{*}{$\begin{array}{l}\text { Ho-Huu et al. } \\
{[21]}\end{array}$} & \multirow{4}{*}{$\begin{array}{l}4 \\
{\left[\theta_{1} / \theta_{2}\right]_{s}} \\
{\left[t_{1} / t_{2}\right]_{s}}\end{array}$} & {$[45 /-45]_{s}$} & \multirow{2}{*}{19.49077} & \multirow{2}{*}{1260} \\
\hline & & {$[10.242 / 39.757]_{\mathrm{s}}$} & & \\
\hline \multirow{2}{*}{ Present study } & & {$[45 /-45]_{s}$} & \multirow{2}{*}{19.5043} & \multirow{2}{*}{84} \\
\hline & & {$[9.5996 / 40.4004]_{\mathrm{s}}$} & & \\
\hline
\end{tabular}

\subsection{Optimum Fiber Angles for Maximizing the Buckling Load}

This section presents the optimum fiber orientation angles of the laminated composite plates $(12 \times 12$ elements) subjected to biaxial compression with simply supported boundary conditions. The objective is to maximize the biaxial buckling load considering only the fiber angles as design variables.

Table 5 and Figure 4 present the effects of the optimum fiber orientation angles of laminated composite plates on the critical biaxial buckling load factor $\left(\lambda_{c r}\right)$. In this case, three layers are considered while varying the $a / h$ ratio. As can be seen, the optimum fiber angles do not change when the $a / h$ ratio is increased. The buckling load of the laminated plates is decreased when the $a / h$ ratio increases. The change of $a / h$ ratio doesn't have any effect on the optimum fiber angles of the laminated composite plates.

\subsection{Optimum Fiber Angles and Thicknesses for Maximum Buckling Load}

The objective in this section is to maximize the biaxial buckling load factor in the case of mixed design variables (i.e. both fiber angles and thicknesses) of the laminated composite plates $(12 \times 12$ elements) subjected to biaxial compression with simply supported boundary conditions.

Table 5. Effect of $a / h$ ratio on the optimum fiber angle of the laminated composite plates.

\begin{tabular}{|c|c|c|c|c|c|c|c|c|c|}
\hline \multirow{2}{*}{$a / h$} & \multicolumn{3}{|c|}{4 layers } & \multicolumn{3}{|c|}{6 layers } & \multicolumn{3}{c|}{10 layers } \\
\cline { 2 - 10 } & {$\left[\theta_{1} / \theta_{2}\right]_{s}$} & $\lambda_{c r}$ & NSA & $\begin{array}{c}{\left[\theta_{1} /\right.} \\
\left.\theta_{2} / \theta_{3}\right]_{s}\end{array}$ & $\lambda_{c r}$ & NSA & $\begin{array}{l}{\left[\theta_{1} / \theta_{2} / \theta_{3} /\right.} \\
\left.\theta_{4} / \theta_{5}\right]_{s}\end{array}$ & $\lambda_{c r}$ & NSA \\
\hline 10 & {$[45 /-45] \mathrm{s}$} & 14.871 & 68 & $\begin{array}{c}{[45 /-} \\
45 /-45] \mathrm{s}\end{array}$ & 18.2 & 141 & $\begin{array}{c}{[45 /-45 /-} \\
45 /-45 / 45] \mathrm{s}\end{array}$ & 19.5238 & 242 \\
\hline 15 & {$[45 /-45] \mathrm{s}$} & 5.6066 & 39 & $\begin{array}{c}{[45 /-} \\
45 /-45] \mathrm{s}\end{array}$ & 7.0367 & 186 & $\begin{array}{c}{[45 /-45 /-} \\
45 /-45 / 45] \mathrm{s}\end{array}$ & 7.5743 & 222 \\
\hline 20 & {$[45 /-45] \mathrm{s}$} & 2.6246 & 64 & $\begin{array}{c}{[45 /-} \\
45 /-45] \mathrm{s}\end{array}$ & 3.328 & 124 & $\begin{array}{c}{[45 /-45 /-} \\
45 /-45 / 45] \mathrm{s}\end{array}$ & 3.5858 & 204 \\
\hline 30 & {$[45 /-45] \mathrm{s}$} & 0.8458 & 38 & $\begin{array}{c}{[45 /-} \\
45 /-45] \mathrm{s}\end{array}$ & 1.0804 & 86 & $\begin{array}{c}{[45 /-45 /-} \\
45 /-45 / 45] \mathrm{s}\end{array}$ & 1.1641 & 110 \\
\hline 50 & {$[45 /-45] \mathrm{s}$} & 0.4446 & 43 & $\begin{array}{c}{[45 /-} \\
45 /-45] \mathrm{s}\end{array}$ & 0.2456 & 103 & $\begin{array}{c}{[45 /-45 /-} \\
45 /-45 / 45] \mathrm{s}\end{array}$ & 0.2644 & 191 \\
\hline
\end{tabular}




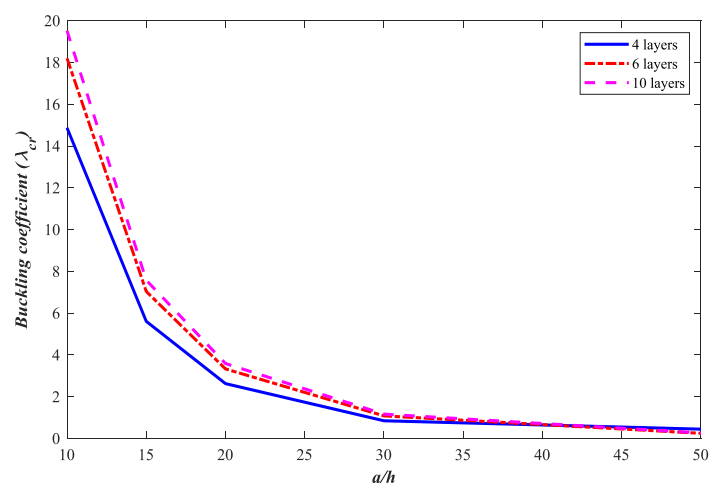

Fig. 4. Effect of the length to thickness ratio on the biaxial buckling load factor.

Table 6 illustrates the optimum results of the fiber angles and thicknesses $\left(\theta_{i}^{0}, t_{i}\right)$ of the laminated composite plates. As can be seen, the optimum fiber angle of each lamina is $\pm 45^{\circ}$ for all cases and the optimum thickness of the [45/-45/-45/45] plate is similar to that of the [45/-45/45] plate with the same maximum biaxial buckling load factor $\lambda_{c r}=19.5043$.

Figure 5 presents the comparison of the number of structural analyses (NSA) for various number of layers of the composite plate. From the results of Table 6 and Figure 4, it is clear that the buckling load factor of the composite plate with 6 layers is slightly higher than that of the plates with 3 and 4 layers. In this case, the convergence history of the plate with 4 layers is the fastest among the three cases with only 84 iterations while for the plate with 3 layers it is 208 iterations and for the plate with 6 layers it is 137 iterations.

Table 6. The optimal results of laminated composite plates for biaxial buckling load factor

\begin{tabular}{|c|c|c|c|}
\hline No of layers & {$\left[\theta_{i}^{0} ; t_{i}\right]$} & $\lambda_{c r}$ & NSA \\
\hline \multirow{2}{*}{$\begin{array}{l}3 \\
{\left[\theta_{1} / \theta_{2} / \theta_{3}\right],\left[t_{1} / t_{2} / t_{3}\right]}\end{array}$} & {$[45 /-45 / 45]$} & \multirow[t]{2}{*}{19.5043} & \multirow[t]{2}{*}{208} \\
\hline & {$[0.0096 / 0.0808 / 0.0096]$} & & \\
\hline \multirow{2}{*}{$\begin{array}{l}4 \\
{\left[\theta_{1} / \theta_{2}\right]_{s},\left[t_{1} / t_{2}\right]_{s}}\end{array}$} & {$[45 /-45]_{s}$} & \multirow[t]{2}{*}{19.5043} & \multirow[t]{2}{*}{84} \\
\hline & {$[0.0096 / 0.0404]_{\mathrm{s}}$} & & \\
\hline \multirow{2}{*}{$\begin{array}{l}6 \\
{\left[\theta_{1} / \theta_{2} / \theta_{3}\right]_{s},\left[t_{1} / t_{2} / t_{3}\right]_{s}}\end{array}$} & {$[-45 / 45 / 45]_{s}$} & \multirow[t]{2}{*}{19.590} & \multirow[t]{2}{*}{137} \\
\hline & {$[0.0094 / 0.0054 / 0.0352]_{s}$} & & \\
\hline
\end{tabular}

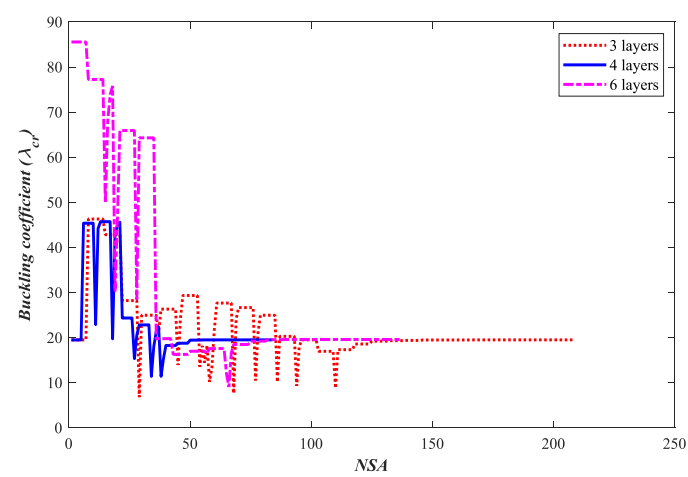

Fig. 5. Convergence histories of the buckling coefficient for composite plates with various numbers of layers. 
The effect of $a / h$ ratio on the optimum fiber angles and thicknesses of the laminated composite plates subjected to biaxial load with 3, 4 and 6 layers is presented in Tables 7-9.

From these tables, it is obvious that the biaxial buckling load of the 6-layer plate is the highest among the three cases. Moreover, the buckling load is decreased when a/h ratio increases. The response of the plates with large number of layers is slightly affected in terms of the biaxial buckling load. The optimization of the 4-layer plate is the fastest in terms of convergence rate. This is illustrated in Figure 6.

Examining the data in Tables 7-9, it is found that when the a/h ratio increases the optimum fiber angles do not change and the optimum thickness ratio (thickness of inner layers/thickness of outer layers) shows a minor change. The optimum thickness ratio of the inner layers/outer layers $\left(t_{i}^{\text {inner }} / t_{i}^{\text {outer }}\right)$ is approximately 4 .

Table 7. Effect of $a / h$ ratio on the optimum fiber angle and thickness of the 3-layer plate.

\begin{tabular}{|l|l|l|l|l|}
\hline$a / h$ & $\begin{array}{l}\text { Optimum fiber } \\
\text { angles } \\
{\left[\theta_{1} / \theta_{2} / \theta_{3}\right]}\end{array}$ & $\begin{array}{l}\text { Optimum thickness } \\
{\left[t_{1} / t_{2} / t_{3}\right]}\end{array}$ & $\lambda_{c r}$ & NSA \\
\hline$a / h=10$ & {$[45 /-45 / 45]$} & {$[0.0096 / 0.0808 / 0.0096]$} & 19.5043 & 208 \\
\hline$a / h=15$ & {$[45 /-45 / 45]$} & {$[0.0066 / 0.0534 / 0.0066]$} & 7.5743 & 159 \\
\hline$a / h=20$ & {$[45 /-45 / 45]$} & {$[0.005 / 0.04 / 0.005]$} & 3.58593 & 188 \\
\hline$a / h=30$ & {$[45 /-45 / 45]$} & {$[0.0034 / 0.0265 / 0.0034]$} & 1.16427 & 194 \\
\hline$a / h=50$ & {$[45 /-45 / 45]$} & {$[0.0021 / 0.016 / 0.0021]$} & 0.26448 & 278 \\
\hline
\end{tabular}

Table 8. Effect of $a / h$ ratio on the optimum fiber angle and thickness of the 4-layer plate.

\begin{tabular}{|l|l|l|l|l|}
\hline$a / h$ & $\begin{array}{l}\text { Optimum fiber angles } \\
{\left[\theta_{1} / \theta_{2}\right]_{s}}\end{array}$ & $\begin{array}{l}\text { Optimum thickness } \\
{\left[t_{1} / t_{2}\right]_{s}}\end{array}$ & $\lambda_{c r}$ & NSA \\
\hline$a / h=10$ & {$[45 /-45]_{\mathrm{s}}$} & {$[0.0096 / 0.0404]_{\mathrm{s}}$} & 19.5043 & 84 \\
\hline$a / h=15$ & {$[45 /-45]_{\mathrm{s}}$} & {$[0.0066 / 0.0268]_{\mathrm{s}}$} & 7.5743 & 102 \\
\hline$a / h=20$ & {$[45 /-45]_{\mathrm{s}}$} & {$[0.005 / 0.02]_{\mathrm{s}}$} & 3.58583 & 113 \\
\hline$a / h=30$ & {$[45 /-45]_{\mathrm{s}}$} & {$[0.0034 / 0.0132]_{\mathrm{s}}$} & 1.16427 & 127 \\
\hline$a / h=50$ & {$[45 /-45]_{\mathrm{s}}$} & {$[0.0021 / 0.0079]_{\mathrm{s}}$} & 0.26447 & 137 \\
\hline
\end{tabular}

Table 9. Effect of $a / h$ ratio on the optimum fiber angle and thickness of the 6-layer plate.

\begin{tabular}{|l|l|l|l|l|}
\hline$a / h$ & $\begin{array}{l}\text { Optimum fiber angles } \\
{\left[\theta_{1} / \theta_{2} / \theta_{3}\right]_{s}}\end{array}$ & $\begin{array}{l}\text { Optimum thickness } \\
{\left[t_{1} / t_{2} / t_{3}\right]_{s}}\end{array}$ & $\lambda_{c r}$ & NSA \\
\hline$a / h=10$ & {$[-45 / 45 / 45]_{\mathrm{s}}$} & {$[0.0094 / 0.0054 / 0.0352]_{\mathrm{s}}$} & 19.590 & 137 \\
\hline$a / h=15$ & {$[-45 /-45 / 45]_{\mathrm{s}}$} & {$[0.0033 / 0.0033 / 0.0268]_{\mathrm{s}}$} & 7.607 & 406 \\
\hline$a / h=20$ & {$[-45 /-45 / 45]_{\mathrm{s}}$} & {$[0.0025 / 0.0025 / 0.02]_{\mathrm{s}}$} & 3.6012 & 212 \\
\hline$a / h=30$ & {$[-45 /-45 / 45]_{\mathrm{s}}$} & {$[0.00169 / 0.00169 / 0.01328]_{\mathrm{s}}$} & 1.1692 & 351 \\
\hline$a / h=50$ & {$[45 /-45 /-45]_{\mathrm{s}}$} & {$[0.00207 / 0.00397 / 0.003957]_{\mathrm{s}}$} & 0.2645 & 594 \\
\hline
\end{tabular}




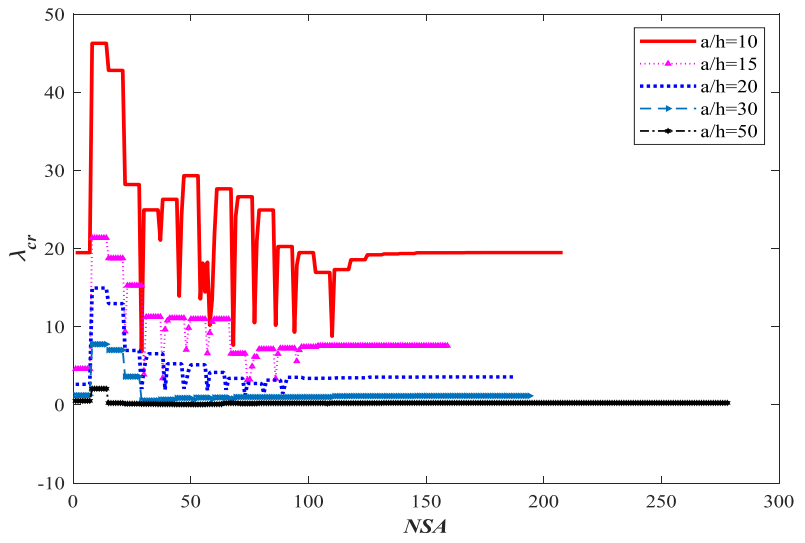

a. 3 layers

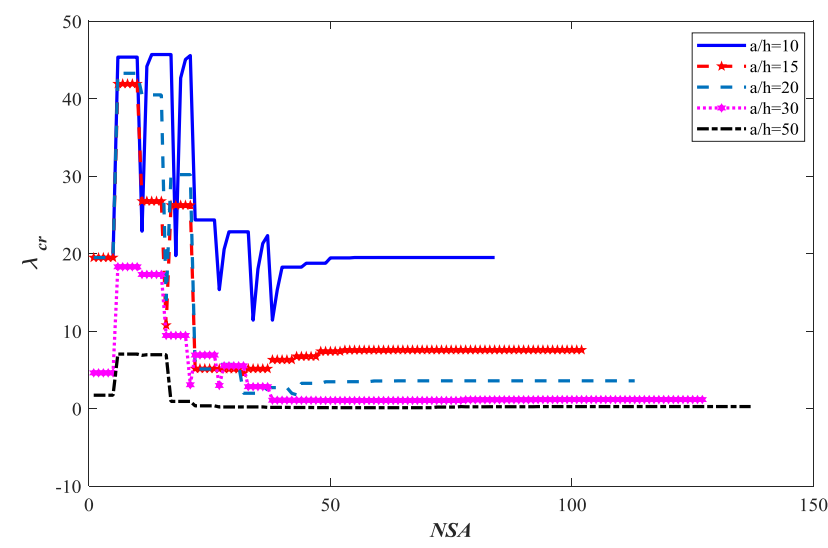

b. 4 layers

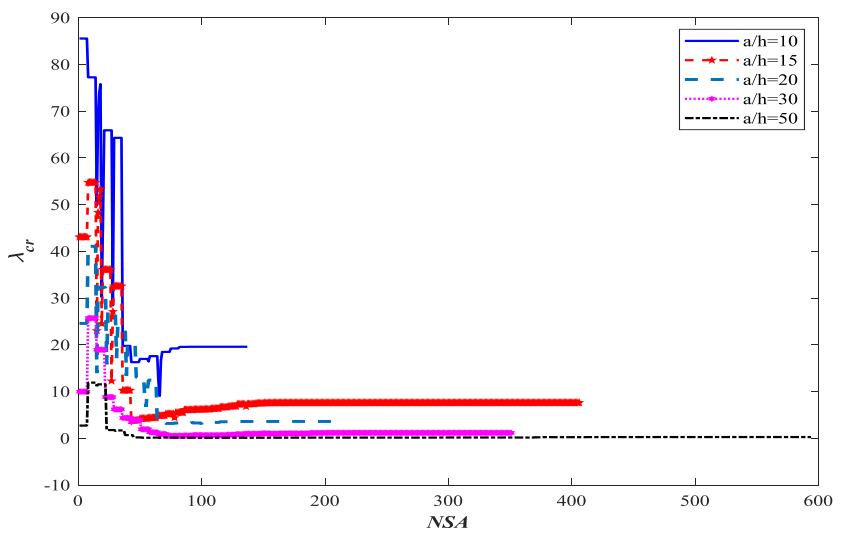

c. 6 layers

Fig. 6. Convergence histories of the buckling load for composite plates with different $a / h$ ratios. 


\section{Conclusions}

In this paper, a new optimization procedure for the laminated composite plates is proposed which uses the gradient-based interior point algorithm to obtain maximum biaxial buckling load considering the fiber angles and thickness as design variables. Some conclusions are drawn from this study as follows:

- The optimum fiber angle of each lamina of the composite plates subjected to biaxial load is $\pm 45^{\circ}$ when considering only fiber angle variables as design variables and when considering fiber angle and thickness as design variables.

- The plates with large number of layers are slightly affected in terms of the maximum biaxial buckling load. The 4-layer plate has the fastest convergence rate.

- The variations of $a / h$ ratio have practically no effect on the optimum fiber angles and slightly affect the optimum thickness ratio of the laminated composite plates subjected to biaxial load.

\section{Acknowledgements}

This research is funded by the National Science and Technology Program of Vietnam for the period of 2016-2020 "Research and development of science education to meet the requirements of fundamental and comprehensive reform education of Vietnam" under Grant number KHGD/16-20.ĐT.032. The authors are grateful for this support.

Pham Dinh Nguyen acknowledges the support of the Domestic Master/ PhD Scholarship Programme of Vingroup Innovation Foundation also.

\section{References}

[1] J. Wang, K.M. Liew, M.J. Tan, S. Rajendran, Analysis of rectangular laminated composite plates via FSDT meshless method, Int. J. Mech. Sci. 44 (2002) 1275-93.

[2] A.J.M. Ferreira, L.M. Castro, C.M.C. Roque, J.N. Reddy, S. Bertoluzza, Buckling analysis of laminated plates by wavelets, Comput. Struct. 89 (2011) 626-30.

[3] H. Nguyen-Van, N. Mai-Duy, W. Karunasena, T. Tran-Cong, Buckling and vibration analysis of laminated composite plate/shell structures via a smoothed quadrilateral flat shell element with in-plane rotations, Comput. Struct. 89 (2011) 612-25.

[4] C.H. Thai, H. Nguyen-Xuan, N. Nguyen-Thanh, T.H. Le, T. Nguyen-Thoi, T. Rabczuk, Static, free vibration, and buckling analysis of laminated composite Reissner-Mindlin plates using NURBS-based isogeometric approach, Int. J. Numer. Meth. Eng. 91 (2012) 571-603.

[5] A.A. Khdeir, L. Librescu, Analysis of symmetric cross-ply elastic plates using a higher-order theory: part II: buckling and free vibration, Compos. Struct. 9 (1988) 259-277.

[6] M.E. Fares, A.M. Zenkour, Buckling and free vibration of non-homogeneous composite cross-ply laminated plates with various plate theories, Compos. Struct. 44 (1999) 279-287.

[7] A. Chakrabarti, A.H. Sheikh, Buckling of laminated composite plates by a new element based on higher order shear deformation theory, Mech. Adv. Mater. Struct. 10 (2003) 303-17.

[8] N.D. Duc, J. Lee, T. Nguyen-Thoi, P.T. Thang, Static response and free vibration of functionally graded carbon nanotube-reinforced composite rectangular plates resting on Winkler-Pasternak elastic foundations, J. Aeros. Sci. Techno. 68 (2017) 391-402.

[9] N.D. Duc, V.D. Quang, P.D. Nguyen, T.M. Chien, Nonlinear dynamic response of functionally graded porous plates on elastic foundation subjected to thermal and mechanical loads, J. Appl. Comput. Mech. 4(4) (2018) 245259. 
[10] N.L. Le, T.P. Nguyen, H.N. Vu, T.T. Nguyen, M.D. Vu, An analytical approach of nonlinear thermo-mechanical buckling of functionally graded graphene-reinforced composite laminated cylindrical shells under compressive axial load surrounded by elastic foundation, J. Appl. Comput. Mech. 6(2) (2020) 357-372.

[11] T.B. Kermanidis, G.N. Labeas, Static and stability analysis of composite plates by a semi-analytical method, Compos. Struct. 57(4) (1995) 673-679.

[12] R.P. Mohammad, E. Arabi, On the geometrically nonlinear analysis of composite axisymmetric shells, J. Appl. Comput. Mech. 4 (2018) 402-419.

[13] H.T. Hu, B.H. Lin, Buckling optimization of symmetrically laminated plates with various geometries and end conditions, Compos. Sci. Technol. 55 (1998) 277-285.

[14] G.B. Chai, K.T. Ooi, W. Khong, Buckling strength optimization of laminated composite plates, Compos. Struct. 46 (1) (1993) 77-82.

[15] R.L. Riche, R.T. Haftka, Optimization of laminate stacking sequence for buckling load maximization by genetic algorithm, A.I.A.A. J. 31 (5) (1993) 951-956.

[16] Z.Jing, X. Fan, Q. Sun, Stacking sequence optimization of composite laminates for maximum buckling load using permutation search algorithm, Compos. Struct. 121 (2015) 225-236.

[17] H.G. Bargh, M.H. Sadr, Stacking sequence optimization of composite plates for maximum fundamental frequency using particle swarm optimization algorithm, Meccanica. 47 (2012) 719-730.

[18] F.S. Almeida, Stacking sequence optimization for maximum buckling load of composite plates using harmony search algorithm, Compos. Struct. 143 (2016) 287-299.

[19] C. Huang, B. Kroplin, On the optimization of composite laminated plates, Eng. Computation. 12 (5) (1995) 403414.

[20] M. Akbulut, F.O. Sonmez, Optimum design of composite laminates for minimum thickness, Compos. Struct. 86 (21-22) (2008) 1974-1982.

[21] V. Ho-Huu, T.D. Do-Thi, H. Dang-Trung, T. Vo-Duy, T. Nguyen-Thoi, Optimization of laminated composite plates for maximizing buckling load using improved differential evolution and smoothed finite element method, Compos. Struct. 146 (2016) 132-147.

[22] G. Papazafeiropoulos, M. Muñiz-Calvente, E. Martínez-Pañeda, Abaqus2Matlab: A suitable tool for finite element post-processing, Adv. Eng. Softw. 105 (2017) 9-16.

[23] K.N.V, Chandrasekhar, V. Bhikshma, K.U. Bhaskara Reddy, Topology optimization of laminated composite plates and shells using optimality criteria, J. Appl. Comput. Mech. 7(1) (2021). 